\title{
A Critical Interaction between Dopamine D2 Receptors and Endocannabinoids Mediates the Effects of Cocaine on Striatal GABAergic Transmission
}

\author{
Diego Centonze', Natalia Battista ${ }^{2}$, Silvia Rossi', Nicola B Mercuri', Alessandro Finazzi-Agrò' ${ }^{2}$, \\ Giorgio Bernardi ${ }^{1}$, Paolo Calabresi*, ${ }^{*, 5}$ and Mauro Maccarrone*,3,4,5 \\ 'Clinica Neurologica, Dipartimento di Neuroscienze, Università Tor Vergata \& IRCCS Fondazione Santa Lucia, Rome, Italy; ${ }^{2}$ Dipartimento di \\ Medicina Sperimentale e Scienze Biochimiche, Università Tor Vergata, Rome, Italy; ${ }^{3}$ Dipartimento di Scienze Biomediche, Università di Teramo, \\ Teramo, Italy; ${ }^{4}$ IRCCS Centro per la Neurobiologia Sperimentale C Mondino, Mondino-Tor Vergata-Santa Lucia, Rome, Italy
}

\begin{abstract}
Compelling evidence indicates that endocannabinoids are implicated in drug addiction. In the present study, we have addressed the interaction between cocaine and endocannabinoid system by means of neurochemical and neurophysiological experiments in rat brain slices. Using gas chromatography-electron impact mass spectrometry, we have found that cocaine increased the levels of the endocannabinoid anandamide in the striatum, a brain area primarily involved in the compulsive drug-seeking and drug-taking behaviors typical of addiction. This effect was attenuated by pharmacological inhibition of D2-like receptors but not DI-like receptors, and it was mimicked by D2-like but not DI-like receptor stimulation. The cocaine-induced increase in anandamide concentrations was attributable to both stimulation of its synthesis and inhibition of its degradation, as suggested by the ability of cocaine and quinpirole, a D2-like receptor agonist, to enhance the activity of NAPE-phospholipase D and to inhibit fatty acid amide hydrolase. By means of electrophysiological recordings from single striatal neurons, we have then observed that the ability of cocaine to inhibit, via D2-like receptors, GABA transmission was partially prevented following blockade of cannabinoid receptors, suggesting that endocannabinoids may act as downstream effectors in the action of cocaine in the striatum. Understanding the molecular and physiological effects of drugs of abuse in the brain is essential for the development of effective strategies against addiction.
\end{abstract}

Neuropsychopharmacology (2004) 29, |488-1497, advance online publication, 2 I April 2004; doi: 10.1038/sj.npp. 1300458

Keywords: addiction; anandamide; CBI receptors; GABA transmission; IPSC; psychostimulants

\section{INTRODUCTION}

Cannabinoid system has been implicated in a number of neuropsychiatric conditions, including dopamine (DA)related disorders such as schizophrenia (Emrich et al, 1997), Parkinson's disease (Gubellini et al, 2002; Maccarrone et al, 2003a), and drug addiction (Ledent et al, 1999; De Vries et al, 2001; Maldonado and Rodriguez de Fonseca,

\footnotetext{
*Correspondence: P Calabresi, Dipartimento di Neuroscienze, Università Tor Vergata, Via Montpellier I, 00133 Rome, Italy, Tel: + 390672596010 , Fax: + 39067259 6006,

E-mail: paolo.calabresi@uniroma2.it

M Maccarrone, Dipartimento di Scienze Biomediche, Università di Teramo, Piazza A Moro 45, 64100 Teramo, Italy, Tel: + $39086 \mid 266$ 875, Fax: + 39067259 6468, E-mail: maccarrone@vet.unite.it

${ }^{5}$ These authors should be considered equal senior authors

Received 9 September 2003; revised 4 March 2004; accepted 5 March 2004

Online publication: 12 March 2004 at http://www.acnp.org/citations/ Npp03 1204034 I /default.pdf
}

2002). The involvement of endocannabinoids in drug addiction is likely to reflect the effects of these compounds in the so-called 'reward circuitry', which includes midbrain DA neurons and their target structures (Berke and Hyman, 2000; Everitt and Wolf, 2002; Maldonado and Rodriguez de Fonseca, 2002). With respect to the role of endocannabinoids in opiate addiction, it has been reported that the rewarding effects of morphine are blocked by both pharmacological (Chaperon et al, 1998) and genetic inactivation of cannabinoid CB1 receptors (Martin et al, 2000), while blockade of CB1 receptors abolishes morphine intravenous self-administration (Ledent et al, 1999), and precipitates withdrawal symptoms in morphine-dependent rats (Navarro et al, 1998).

Although matter of less extensive investigations, also the involvement of cannabinoid system in psychostimulant addiction has been addressed. $\Delta^{9}$-tetrahydrocannabinol (THC) self-administration in monkeys is greatly facilitated after previous acquisition of cocaine self-administration (Tanda et al, 2000; Maldonado and Rodriguez de Fonseca, 2002), while chronic cannabinoid administration produces 
cross-sensitization not only to the locomotor effects of opioids (Pontieri et al, 2001) but also of amphetamine (Gorriti et al, 1999). Finally, pharmacological blockade of cannabinoid $\mathrm{CB} 1$ receptors prevents relapse to cocaineseeking behavior induced by re-exposure to the drug, while stimulation of these receptors facilitates it (De Vries et al, 2001).

Although some of these results might indicate that endocannabinoids act as critical downstream effectors of the cocaine action, the molecular and cellular bases of the cocaine-endocannabinoid interaction are still unknown. The striatum contains high levels of both cannabinoid CB1 receptors and DA receptors (Piomelli, 2003), and represents therefore an ideal structure to study the interplay between these two transmitter systems with respect to cocaine effects. Accordingly, the effects of cocaine in the brain are mainly mediated by the stimulation of DA receptors (Berke and Hyman, 2000), which are important modulators of synaptic transmission in the striatum (Calabresi et al, 2000). We have recently shown that both cocaine and amphetamine inhibit GABA transmission in this structure, an effect primarily attributable to the activation of DA D2 receptors located on presynaptic terminals of GABAergic interneurons (Centonze et al, 2002). Since GABAergic terminals and GABAergic interneurons seem to be also the preferential location of CB1 receptors in the striatum (Piomelli, 2003), a functional interaction between cannabinoid and DA receptors might occur at this level.

In the present study, therefore, we addressed this important issue by means of biochemical and electrophysiological experiments in rat brain slices. Our results show that cocaine, through the stimulation of DA D2-like receptors, increases the levels of the endocannabinoid anandamide (AEA) in the striatum, a brain area primarily involved in the compulsive drug-seeking and drug-taking behaviors typical of addiction (Berke and Hyman, 2000; Everitt and Wolf, 2002; Gerdeman et al, 2003). The cocaineinduced increase in AEA concentrations was attributable to both stimulation of its synthesis and inhibition of its degradation, and facilitated, through the activation of cannabinoid receptors, the DA D2-receptor-dependent inhibition of GABA transmission induced by cocaine.

\section{MATERIALS AND METHODS}

Adult male Wistar rats (150-250 g) were used for all the biochemical and electrophysiological experiments. All the experiments were conducted in conformity with the European Communities Council Directive of November 1986 (86/609/EEC).

\section{Determination of Anandamide Levels}

The endogenous levels of anandamide (AEA) in the striatum were determined by gas chromatography-electron impact mass spectrometry (GC/MS) (Maccarrone et al, 2001). Immediately after decapitation, corticostriatal brain slices $(200 \mu \mathrm{m})$ were prepared with the use a vibratome and kept in artificial cerebrospinal fluid (ACSF), whose composition was (in mM): (126) $\mathrm{NaCl},(2.5) \mathrm{KCl},(1.2) \mathrm{MgCl}_{2},(1.2)$ $\mathrm{NaH}_{2} \mathrm{PO}_{4}$, (2.4) $\mathrm{CaCl}_{2}$, (11) glucose, (25) $\mathrm{NaHCO}_{3}$. The temperature of ACSF was maintained at $35^{\circ} \mathrm{C}$ and it was gassed with $\mathrm{O}_{2} / \mathrm{CO}_{2}(95 / 5 \%)$. Slices were bathed for $10 \mathrm{~min}$ in the presence or in the absence of specific pharmacological treatments, then they were washed in phosphatebuffered saline (precooled at $4{ }^{\circ} \mathrm{C}$ ), frozen in liquid nitrogen and kept at $-70^{\circ} \mathrm{C}$ until processed. Lipids were extracted from frozen tissues and were injected into a Carlo Erba model HRGC5160 gas chromatograph (Rome, Italy), equipped with a BP5 silica capillary column ( $30 \mathrm{~m} \times 0.25 \mathrm{~mm}$ i.d.) from SGE (Milan, Italy), and interfaced with a VG Micromass model QUATTRO spectrometer (Manchester, UK). Analyses were performed in a 'split-less' mode at temperatures rising from 70 to $250^{\circ} \mathrm{C}$, at a rate of $30^{\circ} \mathrm{C} / \mathrm{min}$. The identity of AEA was assessed by comparison of the retention times and the mass spectra recorded at $70 \mathrm{eV}$ with those of authentic standards. Quantitation of AEA was achieved by isotope dilution with AEAd4. Calibration solutions and calibration curves were obtained as described (Maccarrone et al, 2001).

\section{Determination of AEA Metabolism and Binding}

The uptake of $\left[{ }^{3} \mathrm{H}\right]$ AEA by the AEA membrane transporter (AMT) was assayed in synaptosomes prepared from corticostriatal slices as reported (Maccarrone et al, 2001, 2003a). Tissues were resuspended in ice-cold $0.32 \mathrm{M}$ sucrose, $5 \mathrm{mM}$ Tris- $\mathrm{HCl}$ buffer ( $\mathrm{pH} 7.4$ ) and were gently disrupted by 10 up-and-down strokes in a Teflon-glass homogenizer (weight: volume ratio $=1: 20$ ). The homogenates were centrifuged at $1000 \mathrm{~g}$ for $5 \mathrm{~min}$, at $4{ }^{\circ} \mathrm{C}$, then supernatants were centrifuged again at $17000 \mathrm{~g}$ for $15 \mathrm{~min}$, at $4{ }^{\circ} \mathrm{C}$. The final pellets were resuspended in $136 \mathrm{mM} \mathrm{NaCl}$, $5 \mathrm{mM} \mathrm{KCl}, 0.16 \mathrm{mM} \mathrm{CaCl}_{2}, 0.1 \mathrm{mM}$ EGTA, $1.3 \mathrm{mM} \mathrm{MgCl}_{2}$, $10 \mathrm{mM}$ glucose, and $10 \mathrm{mM}$ Tris- $\mathrm{HCl}$ buffer $(\mathrm{pH} \mathrm{7.4)}$, at a protein concentration of $3 \mathrm{mg} / \mathrm{ml}$. The activity of AMT was measured using $100 \mu$ synaptosomes and $300 \mathrm{nM}\left[{ }^{3} \mathrm{H}\right] \mathrm{AEA}$ per test.

Anandamide hydrolase (arachidonoylethanolamide amidohydrolase, EC 3.5.1.4; fatty acid amide hydrolase, FAAH) activity was assayed in homogenates of corticostriatal slices by reversed-phase high-performance liquid chromatography, using $5 \mu \mathrm{M}\left[{ }^{3} \mathrm{H}\right] \mathrm{AEA}$ as substrate (Maccarrone et al, 2003a). FAAH activity was expressed as pmol arachidonate released per min per mg protein.

The activity of $N$-acyl-phosphatidylethanolamines (NAPE)-hydrolyzing phospholipase D (phosphatidylcholine phosphatidohydrolase, EC 3.1.4.4; NAPE-PLD) was assayed in homogenates of corticostriatal slices $(50 \mu \mathrm{g} /$ test $)$ according to Moesgaard et al (2000), using $100 \mu \mathrm{M} \mathrm{N}-\left[{ }^{3} \mathrm{H}\right]$ arachidonoyl-phosphatidylethanolamine $\left(\left[{ }^{3} \mathrm{H}\right] \mathrm{NArPE}\right)$ as substrate (Okamoto et al, 2004). NAPE-PLD activity was expressed as pmol $\left[{ }^{3} \mathrm{H}\right] \mathrm{AEA}$ released per min per $\mathrm{mg}$ protein.

The binding of the synthetic cannabinoid $\left[{ }^{3} \mathrm{H}\right] \mathrm{CP} 55,940$ to striatal membranes was determined by using rat membrane fractions prepared, quickly frozen in liquid nitrogen and stored at $-80^{\circ} \mathrm{C}$ for no longer than 1 week as reported (Maccarrone et al, 2003a). These membrane fractions were used in rapid filtration assays with $400 \mathrm{pM}$ agonist, a dose that gives a well-detectable binding in rat striatal membranes (Gubellini et al, 2002; Maccarrone et al, 2003a). The apparent dissociation constant $\left(K_{\mathrm{d}}\right)$ and maximum binding 
$\left(B_{\max }\right)$ values of $\left[{ }^{3} \mathrm{H}\right] \mathrm{CP} 55,940$ were calculated from saturation curves (in the range $0-800 \mathrm{pM}$ ) through nonlinear regression analysis with the Prism 3 program (GraphPAD Sofware for Science, San Diego, CA, USA) (Maccarrone et al, 2003a). $\left[{ }^{3} \mathrm{H}\right] \mathrm{AEA}(223 \mathrm{Ci} / \mathrm{mmol})$ and $\left[{ }^{3} \mathrm{H}\right] \mathrm{CP} 55,940$ (126 Ci/mmol) were from NEN DuPont de Nemours (Köln, Germany); $\left[{ }^{3} \mathrm{H}\right] \mathrm{NArPE}(200 \mathrm{Ci} / \mathrm{mmol})$ was from ARC (St Louis, MO, USA). Biochemical data were expressed as the mean $\pm S D$, and statistical analysis was performed by the Student's $t$-test (ST), through the InStat 3 program (GraphPAD Software for Science, San Diego, CA, USA). The significance level was established at $p<0.05$.

\section{Electrophysiology}

Corticostriatal coronal slices $(200 \mu \mathrm{m})$ were prepared from tissue blocks of the rat brain with the use of a vibratome (Centonze et al, 2002; Picconi et al, 2003). A single slice was then transferred to a recording chamber and submerged in a continuously flowing $\mathrm{ACSF}\left(35^{\circ} \mathrm{C}, 2-3 \mathrm{ml} / \mathrm{min}\right)$ gassed with $95 \% \mathrm{O}_{2}-5 \% \mathrm{CO}_{2}$. The composition of the control solution was (in mM): (126) $\mathrm{NaCl},(2.5) \mathrm{KCl}$, (1.2) $\mathrm{MgCl}_{2}$, (1.2) $\mathrm{NaH}_{2} \mathrm{PO}_{4}$, (2.4) $\mathrm{CaCl}_{2}$, (11) Glucose, (25) $\mathrm{NaHCO}_{3}$.

The striatum could be readily identified under a lowpower magnification, whereas individual neurons were visualized in situ using a differential interference contrast (Nomarski) optical system. This employed an Olympus BX50WI (Japan) noninverted microscope with $\times 40$ water immersion objective combined with an infrared filter, a monochrome CCD camera (COHU 4912), and a PC compatible system for analysis of images and contrast enhancement (WinVision 2000, Delta Sistemi, Italy). Recording pipettes were advanced toward individual striatal cells in the slice under positive pressure and, on contact, tight $\mathrm{G} \Omega$ seals were made by applying negative pressure. The membrane patch was then ruptured by suction and membrane current and potential monitored using an Axopatch 1D patch clamp amplifier (Axon Instruments, Foster City, CA, USA). Whole-cell access resistances measured in voltage clamp were in the range of 5-30 M $\Omega$ prior to electronic compensation $(60-80 \%$ was routinely used).

Whole-cell patch clamp recordings were made with borosilicate glass pipettes ( $1.8 \mathrm{~mm}$ o.d.; $3-5 \mathrm{M} \Omega$ ), both in voltage-clamp and current-clamp configuration. To study spontaneous $\mathrm{GABA}_{\mathrm{A}}$-mediated inhibitory postsynaptic currents (IPSCs), the recording pipettes were filled with internal solution of the following composition $(\mathrm{mM})$ : $\mathrm{CsCl}$ (110), $\mathrm{K}^{+}$-gluconate (30), ethylene glycol-bis ( $\beta$-aminoethyl ether)- $N, N, N^{\prime}, N^{\prime}$-tetra-acetic acid (EGTA; 1.1), HEPES (10), $\mathrm{CaCl}_{2}$ (0.1), Mg-ATP (4), Na-GTP (0.3). MK-801 and CNQX were added to the external solution to block, respectively, NMDA and non-NMDA glutamate receptors. Spontaneous $\mathrm{GABA}_{\mathrm{A}}$-mediated IPSCs were stored by using P-CLAMP 8 (Axon Instruments) and analyzed offline on a personal computer with Mini Analysis 5.1 (Synaptosoft, Leonia, NJ, USA) software. The detection threshold was set at twice the baseline noise. The fact that no false events would be identified was confirmed by visual inspection for each experiment. Offline analysis was performed on spontaneous synaptic events recorded during a fixed time epoch (3$5 \mathrm{~min}$ ), sampled every 5 or $10 \mathrm{~min}$ before (two samplings) and after (3-6 samplings) the application of the drugs. Only cells that exhibited stable IPSC frequencies in control (less than $20 \%$ changes during the two control samplings) were taken into account. For IPSC kinetic analysis, events with peak amplitude between 10 and $30 \mathrm{pA}$ were grouped, aligned by half-rise time, and normalized by peak amplitude. Events with complex peaks were eliminated. In each cell, all events between 10 and $30 \mathrm{pA}$ were averaged to obtain rise times, decay times, and half-widths.

For data presented as the mean $\pm S E M$, statistical analysis was performed using a paired or unpaired Student's $t$-test or Wilcoxon's test. When comparing differences between two cumulative distributions, the Kolmogorov-Smirnov (K-S test) was used. The significance level was established at $p<0.05$.

\section{Drugs}

For both biochemical and electrophysiological experiments, drugs were applied by dissolving them to the desired final concentration in the bathing ACSF. The concentrations of the various drugs were chosen according to previous in vitro studies on corticostriatal brain slices (Centonze et al, 2002; Gubellini et al, 2002), and were, unless otherwise specified in the text or in the figures, as follows: CNQX $(10 \mu \mathrm{M})$, HU $210(1 \mu \mathrm{M})$, SCH23390 $(10 \mu \mathrm{M})$, MK-801 $(30 \mu \mathrm{M})$ (from Tocris Cookson, Bristol, UK), bicuculline $(10 \mu \mathrm{M})$, SKF38393 $(10 \mu \mathrm{M})$, quinpirole $(10 \mu \mathrm{M})$ (from Sigma-RBI, St Louis, USA), cocaine $(10 \mu \mathrm{M})$, L-sulpiride $(3 \mu \mathrm{M})$ (from Sigma, Milan, Italy), SR141716A $(1 \mu \mathrm{M})$ (from Sanofi Recherche, Montpellier, France).

\section{RESULTS}

\section{Effects of Cocaine on AEA Synthesis, Transport, and Degradation}

Cocaine treatment significantly increased the levels of endogenous AEA. Also the activity of NAPE-PLD was increased following cocaine treatment, while FAAH activity decreased and AMT activity was unchanged (Figure 1). Taken together, these results suggest that the cocaineinduced increase in AEA levels was secondary to both increased synthesis and decreased degradation. Accordingly, NAPE-PLD plays a crucial role in AEA synthesis from membrane lipids, while FAAH is responsible for AEA breakdown following its intracellular transport mediated by AMT (Di Marzo et al, 1994; Cadas et al, 1997; Iversen, 2003). It seems noteworthy that the NAPE-PLD activity shown here in rat striatum extends a recent report on mouse brain, which appeared during the preparation of this manuscript (Okamoto et al, 2004).

Remarkably, the cocaine effects on AEA levels and metabolism (NAPE-PLD, AMT, and FAAH activity) were almost completely prevented by blocking DA receptors through the co-application of SCH23390 plus L-sulpiride, antagonists of D1- and D2-like receptors, respectively. The isolated application of L-sulpiride, but not of SCH23390, mimicked this effect, indicating that it was entirely mediated by the stimulation of D2-like receptors (Figure 1). Accordingly, the D2-like receptor agonist quinpirole, but not the D1-like receptor agonist SKF38393, 
a

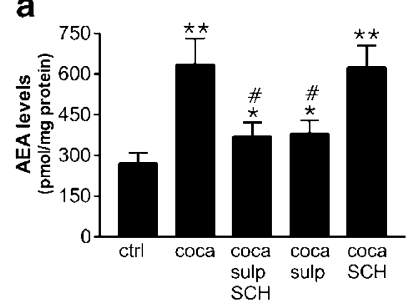

C

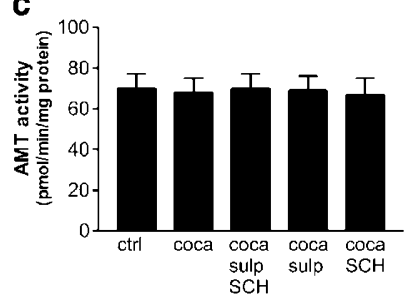

b

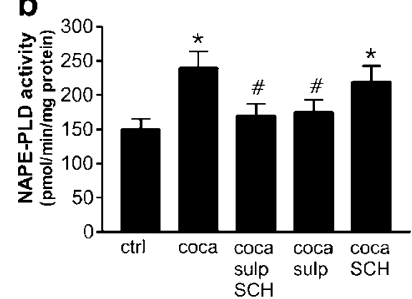

d

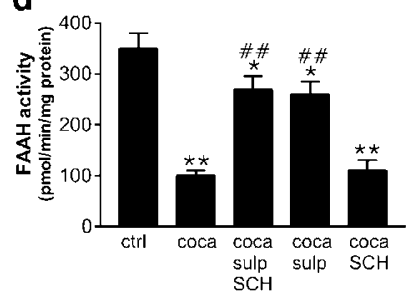

Figure I Cocaine increases AEA levels in the striatum by stimulating its synthesis and inhibiting its degradation. (a) The graph shows that $10 \mu \mathrm{M}$ cocaine increases the levels of AEA in the striatum. Blockade of both DIand D2-like receptors by $\mathrm{SCH} 23390(10 \mu \mathrm{M})$ plus L-sulpiride $(3 \mu \mathrm{M})$ significantly reduced this effect. The cocaine effect was also reduced by $3 \mu \mathrm{M}$ L-sulpiride, but not by $10 \mu \mathrm{M} \mathrm{SCH} 23390$, applied alone. (b) Cocaine increased the activity of NAPE-PLD, an effect inhibited by the blockade of both DI- and D2-like receptors, or by the selective blockade of D2-like receptors. (c, d) The activity of AMT was unaffected by cocaine, while the activity of FAAH was significantly inhibited through the stimulation of DA D2-like receptors. Drugs were applied for $10 \mathrm{~min} ; n=4$ for each experiment; *means $p<0.05$ compared to the control value; **means $p<0.0$ I compared to the control value; \# means $p<0.05$ compared to the cocaine value; \#\# means $p<0.01$ compared to the cocaine value; no symbol means nonsignificant compared to the control value.

increased AEA levels by stimulating NAPE-PLD and inhibiting FAAH, an effect prevented by L-sulpiride but not by SCH23390 (Figure 2).

\section{Effects of Cocaine, Quinpirole, and SKF38393 on Cannabinoid CB1 Receptor Binding}

We also tested the effects of cocaine, quinpirole, and SKF38393 on the binding of the CB1 receptor agonist $\left[{ }^{3} \mathrm{H}\right] \mathrm{CP} 55,940$ to rat striatal membranes. As with AEA levels and metabolism, our results indicate that cocaine and quinpirole, but not SKF38393, significantly altered CB1 receptor function, by increasing its binding properties. Again, these effects were prevented by DA D2- but not D1like receptor blockade (Figure 3). Analysis of the binding of $\left[{ }^{3} \mathrm{H}\right] \mathrm{CP} 55,940$ to striatal membranes, untreated or treated for $10 \mathrm{~min}$ with $10 \mu \mathrm{M}$ cocaine, showed saturation curves superimposable to those recently reported in the same brain area (Maccarrone et al, 2003a). From these saturation curves, apparent $K_{\mathrm{d}}$ values of $340 \pm 70$ and $310 \pm 91 \mathrm{pM}$ $(n=4 ; p>0.05)$ and $B_{\max }$ values of $330 \pm 40$ and $499 \pm 57 \mathrm{fmol} / \mathrm{mg}$ protein $(n=4 ; p<0.05)$ were calculated in controls and cocaine-treated samples, respectively.

\section{Spontaneous Gabaergic Activity in Striatal Neurons}

Electrophysiological recordings with cesium chloridecontaining pipettes allowed detecting, at $-80 \mathrm{mV}$ holding
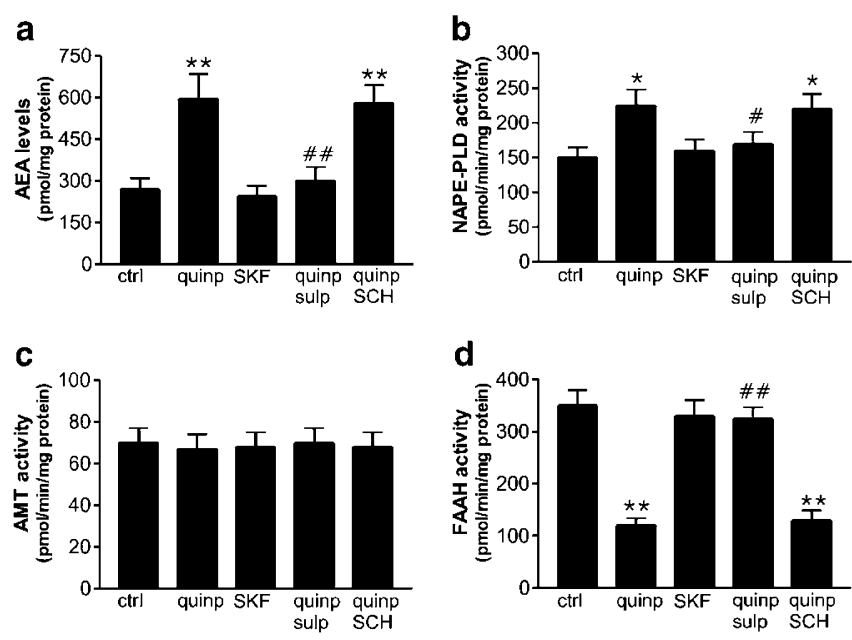

Figure 2 Stimulation of DA D2-like receptors mimics the effects of cocaine on AEA levels and metabolism. Application of the DA D2-like receptor agonist quinpirole $(10 \mu \mathrm{M})$, but not the DA DI-like receptor agonist SKF38393 (IO $\mu \mathrm{M})$, increased AEA levels in the striatum (a), by stimulating AEA synthesis (b) and inhibiting AEA degradation (d). LSulpiride $(3 \mu \mathrm{M})$, but not $\mathrm{SCH} 23390(\mathrm{I} 0 \mu \mathrm{M})$, prevented the quinpirole effects. Drugs were applied for $10 \mathrm{~min} ; n=4$ for each experiment; *means $p<0.05$ compared to the control value; ***means $p<0.0$ I compared to the control value; \# means $p<0.05$ compared to the quinpirole value; \#\# means $p<0.01$ compared to the quinpirole value; no symbol means nonsignificant compared to the control value.
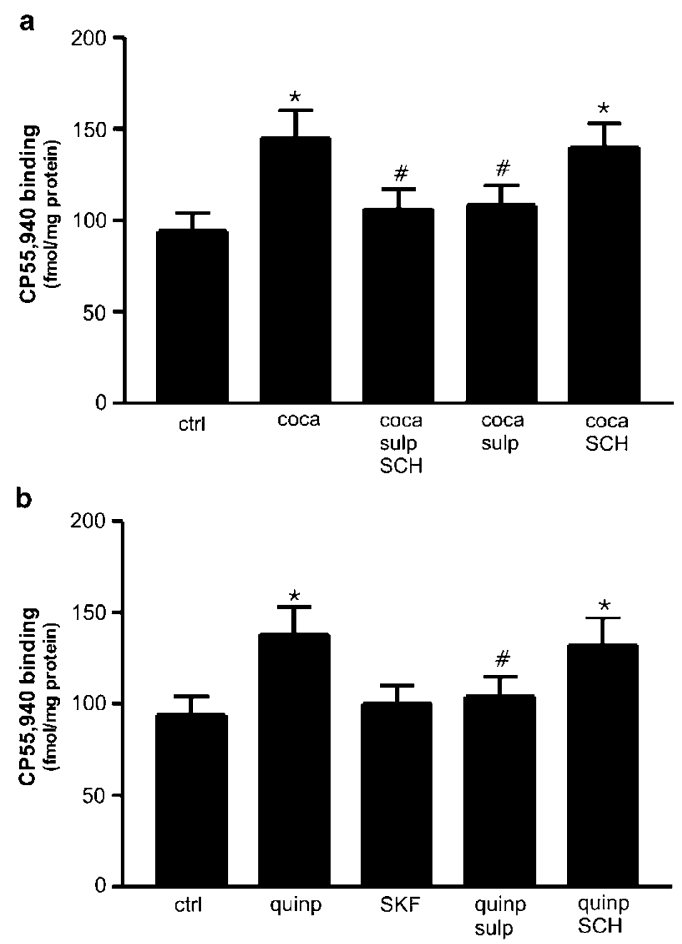

Figure 3 Cocaine and quinpirole increase $C B \mid$ receptor binding in the striatum. (a) The graph shows that $10 \mu \mathrm{M}$ cocaine increases the binding of CP55,940 in the striatum. Blockade of both DI- and D2-like receptors by $\mathrm{SCH} 23390(\mathrm{I} 0 \mu \mathrm{M})$ plus L-sulpiride $(3 \mu \mathrm{M})$ blocked this effect. The cocaine effect was also reduced by L-sulpiride, but not by SCH23390, applied alone. (b) Application of quinpirole $(10 \mu \mathrm{M})$, but not the DA DI-like receptor agonist SKF38393 $(10 \mu \mathrm{M})$, mimicked the effects of cocaine on striatal CP55,940 binding, which were prevented by $3 \mu \mathrm{M}$ L-sulpiride but not by $10 \mu \mathrm{M}$ SCH23390. Drugs were applied for $10 \mathrm{~min} ; n=4$ for each experiments. Symbols as in Figures $\mathrm{I}$ and 2. 
potential (HP) and in the presence of $10 \mu \mathrm{M}$ CNQX plus $30 \mu \mathrm{M}$ MK-801, spontaneous synaptic events that could be blocked by the $\mathrm{GABA}_{\mathrm{A}}$ receptor antagonist bicuculline (Centonze et al, 2003) $(n=14)$. Most events had amplitudes ranging between 5 and $30 \mathrm{pA}$ and had kinetic properties (rise times, dacay time constants, and half-widths) significantly different from glutamate-mediated excitatory postsynaptic currents (not shown). The frequency of spontaneous IPSCs recorded in control conditions ranged between 1.4 and $3.2 \mathrm{~Hz}$.

\section{Involvement of Endocannabinoids in the Effects of Cocaine on Spontaneous IPSCs}

According to a previous report showing that psychostimulants presynaptically inhibit GABA inputs to striatal neurons (Centonze et al, 2002), cocaine (5-10 min) dosedependently reduced the frequency of spontaneous GABAergic IPSCs recorded from striatal slices $(n=17)$. This effect, fully reversible at the wash of the drug, was prevented by preincubation (5-7 $\mathrm{min}$ ) with the D2-like receptor antagonist L-sulpiride $(n=4)$, and was mimicked by the D2-like receptor agonist quinpirole (5-10 $\mathrm{min}, n=15)$ but not by the D1-like receptor agonist SKF38393 (5-10 min, $n=7$ ), confirming that it was mediated by the stimulation of D2-like receptors (Delgado et al, 2000; Centonze et al, 2002) (Figure 4). As expected for a presynaptic site of action, neither cocaine nor quinpirole altered IPSC mean amplitude, rise time, decay time, and half-width (Figure $5 a-d$ ).

Cocaine has been reported to modulate striatal neuron firing activity through a direct interaction with voltagedependent sodium channels (Kiyatkin and Rebec, 2000). In a further set of experiments, therefore, we wanted to see whether this drug, at the concentrations employed in the present study, was able to modulate repetitive firing activity of striatal neurons in an anesthetic-like manner. As shown in Figure $5 \mathrm{e}, 30 \mu \mathrm{M}$ cocaine ( $10 \mathrm{~min}, n=4)$ failed to affect both firing activity and hyperpolarizing response in striatal neurons recorded in the current-clamp mode.

To investigate the possible involvement of endocannabinoids in the D2-mediated effects of cocaine in the striatum, we measured the action of this drug in the presence of the cannabinoid CB1 receptor antagonist SR141716A. Although SR141716A failed to affect the frequency of sIPSCs recorded from striatal neurons $(n=8,7-10 \mathrm{~min})$, it significantly attenuated the cocaine effects. Further application of Lsulpiride was required to restore fully spontaneous IPSC frequency to control values $(n=4)$ (Figure 4$)$.

\section{Effects of the Cannabinoid CB1 Receptor Agonist HU 210 on Striatal Inhibitory Transmission}

To further address the role of cannabinoid CB1 receptors in the modulation of striatal GABA transmission, we also investigated the electrophysiological effects of HU 210, a CB1 receptor agonist, on spontaneous IPSCs recorded from spiny neurons. According to a previous report (Szabo et al, 1998), bath application of this agent (7-10 $\mathrm{min}, n=5)$ reduced IPSC frequency, without altering IPSC mean amplitude, rise time, decay time, and half-width. Preincubation of the slices with SR141716A (5-7 min, $n=7)$

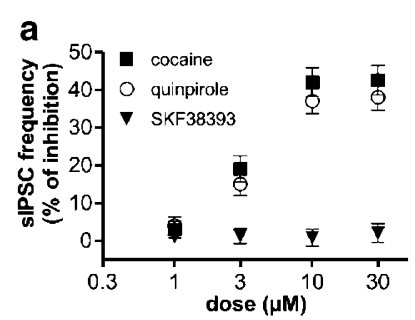

b

c
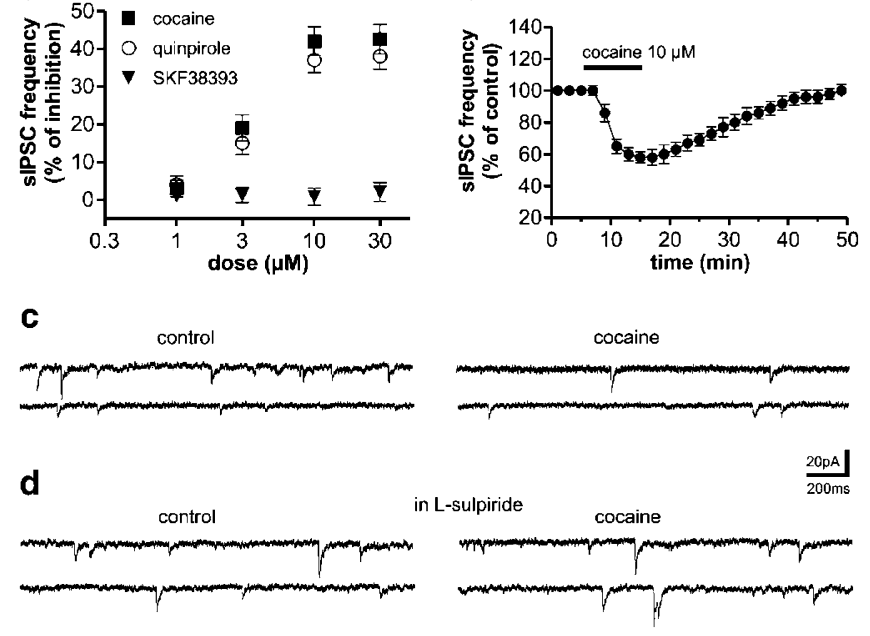

e

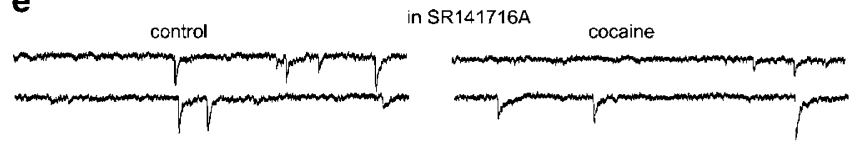

f

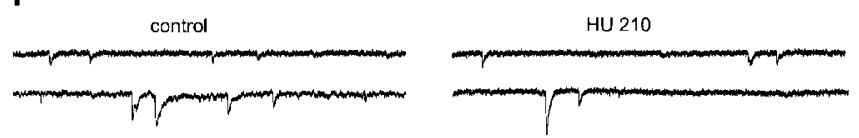

g

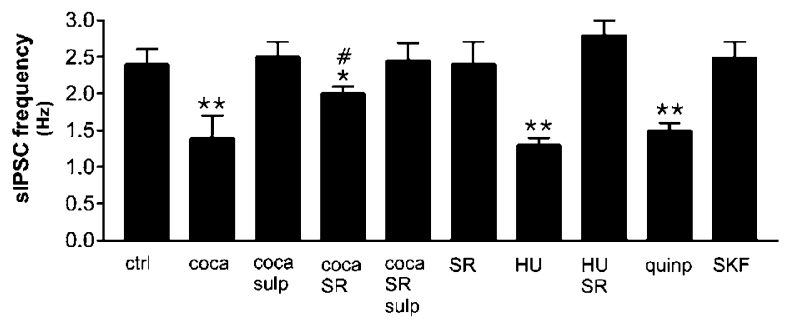

Figure 4 Cocaine depresses inhibitory synaptic transmission in the striatum in a CBI receptor-dependent manner. (a) Cocaine and quinpirole, but not SKF38393, dose-dependently inhibited GABA transmission in the striatum. (b) This graph shows the time course of the effects of cocaine on sIPSC frequency. (c) The electrophysiological traces show that $10 \mu \mathrm{M}$ cocaine reduced the frequency of spontaneous GABA-mediated synaptic currents (downward deflections). (d) In another striatal neuron, preincubation with $3 \mu \mathrm{M}$ L-sulpiride abolished the cocaine effect. (e) The cocaine effect was also significantly attenuated by the $\mathrm{CBI}$ receptor antagonist SRI4I7I6A (I $\mu \mathrm{M})$. (f) Also the CBI receptor agonist HU $210(\mid \mu M)$ depressed sIPSCs recorded from striatal neurons. In (c-f), upper and lower traces on the right and on the left are from single experiments. (g) The histogram describes the effects of several pharmacological treatments on sIPSC frequency. For each experiment $n=$ at least 4. Symbols as in Figure I.

blocked the HU 210-mediated effects, supporting the conclusion that the effects of this antagonist on cocaineinduced IPSC inhibition were indeed mediated by the blockade of CB1 receptors (Figures 4 and 5).

\section{DISCUSSION}

In the present study, we provided evidence that cocaine, through stimulation of DA D2-like receptors, increases 

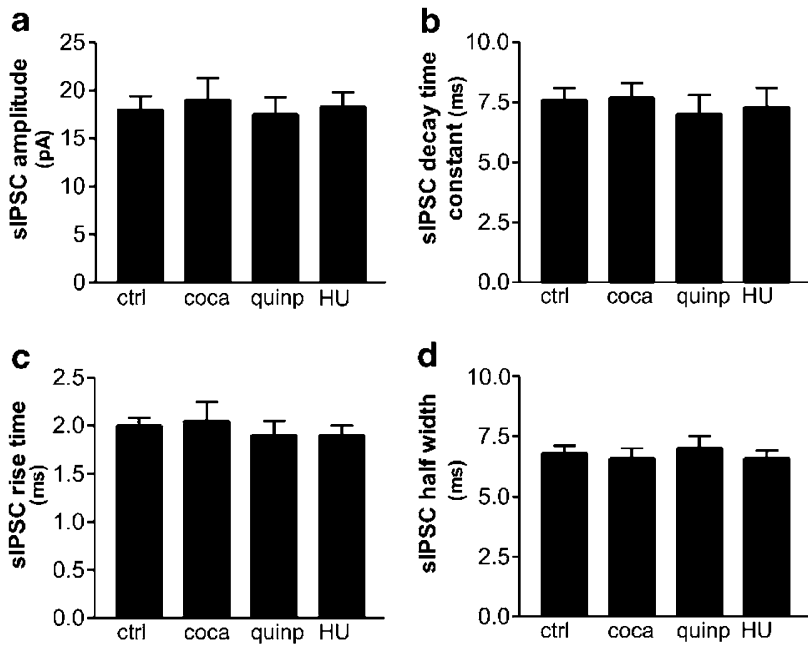

e

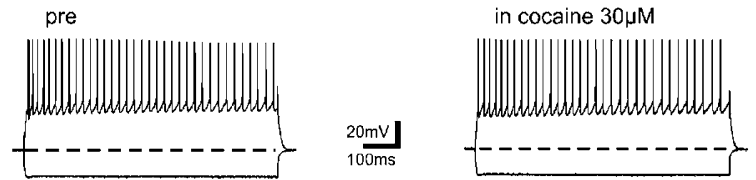

Figure 5 The postsynaptic and intrinsic properties of striatal neurons are unaltered in the presence of cocaine, quinpirole, or $\mathrm{HU} 210$. The histograms describe the effects of $10 \mu \mathrm{M}$ cocaine, $10 \mu \mathrm{M}$ quinpirole, and I $\mu \mathrm{M}$ HU 210 on sIPSC amplitude (a), decay time (b), rise time (c), and half-width (d). (e) In the current-clamp mode, the firing discharge and the hyperpolarizing response evoked in a striatal neuron by intracellular injection of, respectively, positive and negative current $( \pm 600 \mathrm{pA})$ were unaltered in the presence of $30 \mu \mathrm{M}$ cocaine. The dotted line indicates the resting membrane potential of this neuron $(-86 \mathrm{mV})$. For the experiments in (a-d), $n=$ at least 4. No symbol means nonsignificant compared to the control value.

striatal levels of the endocannabinoid AEA, an effect attributable to both increased NAPE-PLD activity and inhibition of FAAH. It should be noted that the levels of AEA found here are comparable to those found in the striatum of healthy and parkinsonian rats (Gubellini et al, 2002), but higher than those found by others in rat brain (Yang et al, 1999). However, our values are in the same range as the endogenous levels of AEA in rat substantia nigra and globus pallidus (Di Marzo et al, 2000), in mouse cortex and hippocampus (Maccarrone et al, 2001), and in mouse uterus (Schmid et al, 1997). In addition, we have recently measured by our GC-MS procedure the levels of AEA in human $\mathrm{T}$ lymphocytes treated or not with progesterone, and found differences superimposable to those found in the same samples in Dr Kunos' laboratory at NIAAA-NIH by liquid chromatography-mass spectrometry (reported in Maccarrone et al, 2003b). Furthermore, the endogenous levels of AEA that we found in human keratinocytes (Maccarrone et al, 2003c) were comparable to those reported by others in mouse epidermal cells (Berdyshev et al, 2000). On the other hand, we have recently summarized evidence against possible pitfalls in the extraction procedure and analysis of our samples (Maccarrone et al, 2004). Of importance is also the fact that the electrophysiological data reported here demonstrate that neuronal cells were healthy and well, ruling out any postmortem release of AEA as a result of brain damage or ischemia.

We also showed that increased levels of AEA significantly contributed to the cocaine-induced presynaptic inhibition of GABA transmission in the striatum, presumably through stimulation of cannabinoid CB1 receptors. This conclusion is mainly based on the finding that SR141716A, a CB1 receptor antagonist, attenuated the effects of cocaine on GABA transmission. Since SR141716A could in principle target additional subtypes of cannabinoid receptors in the striatum, we cannot exclude the involvement of other receptors in the cocaine effects. Another brain cannabinoid receptor different from $\mathrm{CB} 1$ has been shown to be blocked by SR141716A (Breivogel et al, 2001), leaving open the possibility that also this receptor is modulated by cocaine. Yet, the non-CB1 receptor is blocked by SR141716A with lower potency, and is not activated by HU 210 (Breivogel et al, 2001). Therefore, the observations reported here that SR141716A attenuated the cocaine effect at a dose $(1 \mu \mathrm{M})$ widely used to antagonize genuine CB1 receptors (Pertwee and Ross, 2002) and that also HU 210 depressed sIPSCs recorded from striatal neurons (Figure 4) seem to rule out the involvement of non-CB1 receptors.

Enhanced function of $\mathrm{CB} 1$ receptors likely contributed to the effect of cocaine in the striatum, as suggested by the finding that also the binding properties of these receptors increased in response to the administration of this psychostimulant. In particular, the increase of $B_{\max }$ values, but not of $K_{\mathrm{d}}$ values, of $\left[{ }^{3} \mathrm{H}\right] \mathrm{CP} 55,940$ binding in cocainetreated slices suggests that cocaine increased the number of receptors in striatal membranes, but not their affinity for the ligand (Gubellini et al, 2002; Maccarrone et al, 2003a). This hypothesis is in keeping with the notion that CB1 receptors are recycled into the membrane (Hsieh et al, 1999; Coutts et al, 2001). In addition, trafficking of CB1 receptors can also explain their fast modulation upon a short time of treatment, like that (10 min) used in this study (Hsieh et al, 1999; Coutts et al, 2001). In this line it seems noteworthy that the increased number of receptors is paralleled by enhanced levels of the endogenous ligand AEA, suggesting that indeed cocaine treatment engages a larger number of activated CB1 receptors. The possibility that enhancement of AEA levels triggers the increase in receptor number and/ or cell-surface expression remains to be explored.

\section{Involvement of the Striatum in Cocaine Addiction}

The nucleus striatum is a major component of the basal ganglia, primarily involved in sensorimotor functions and also in cognitive and limbic processes (Calabresi et al, 1997; Jog et al, 1999; Packard and Knowlton, 2002). Not surprisingly, therefore, alterations of striatal function are involved in a variety of neurological and psychiatric disorders including Parkinson's disease, Tourette's syndrome, schizophrenia, and drug addiction (Berke and Hyman, 2000; Leckman and Riddle, 2000; Obeso et al, 2000; Carlsson et al, 2001).

Increasing evidence indicates that not only cortical but also subcortical areas are involved in the diverse cognitive, emotional, and motor effects of cocaine and, in particular, the increased locomotor activity and stereotypy caused by 
psychostimulants seem to involve specifically the nucleus striatum (Kelly et al, 1975; Amalric and Koob, 1993; Berke and Hyman, 2000). More recently, synaptic changes in the striatum have been claimed to be involved in the advanced stages of drug addiction, which are characterized by compulsive drug-seeking and drug-taking behaviors despite serious negative consequences (Gerdeman et al, 2003). Accordingly, the striatum plays a critical role in habit learning, a process consisting in the acquisition of increasingly automatic motor actions particularly refractory to devaluation processes (Jog et al, 1999; Canales and Graybiel, 2000). In the striatum, therefore, cocaine is believed to co-opt the neuronal mechanisms involved in habit formation, leading to nearly automatic and repetitive drug assumption even when the outcome becomes frankly undesirable (Berke and Hyman, 2000; Hyman and Malenka, 2001; Gerdeman et al, 2003).

DA plays a critical role in habit formation and in the effects of cocaine in the striatum (Jog et al, 1999; Canales and Graybiel, 2000; Everitt and Wolf, 2002; Gerdeman et al, 2003). This brain area receives profuse dopaminergic innervation arising from midbrain DA neurons and has a very high density of DA receptors (Mansour and Watson, 1995; Surmeier et al, 1996; Centonze et al, 2003). Cocaine increases DA release in the striatum through the blockade of transporter-mediated DA reuptake from nigrostriatal nerve endings and causes rapid induction of striatal c-fos, a commonly used molecular marker for neuronal activity. This effect is fully sensitive to DA receptor blockade (Graybiel et al, 1990; Moratalla et al, 1993), indicating that the actions of cocaine in the striatum are mediated, largely if not exclusively, by the release of endogenous DA and consequent DA receptor stimulation. Other mechanisms, however, might be involved in the pharmacological actions of cocaine in the striatum. Cocaine, in fact, facilitates serotonin and norepinephrine release (Barker and Blakely, 1995; Johanson and Schuster, 1995), two transmitters found to mediate important physiological effects on striatal neurons (Wilms et al, 2001; Pisani et al, 2003). In addition, cocaine has also been found to modulate striatal neuron firing activity in vivo, independently of transmitter release but through a direct interaction with sodium channels (Kiyatkin and Rebec, 2000). Notably, these non-DAmediated effects of cocaine might also play a role in the action of this addictive drug on striatal AEA concentrations, since we have observed that blockade of both D1- and D2like receptors prevented largely, but not entirely, the effects of cocaine on endocannabinoid system.

\section{DA-Cannabinoid Interaction and the Effects of Cocaine in the Striatum}

The recruitment of endocannabinoid system that follows DA receptor stimulation might help to explain its involvement in the neuronal processes underlying cocaine addiction. There is evidence that under certain conditions endocannabinoids can counter the action of D2 receptor stimulation in the brain, suggesting that the D2-receptordependent stimulation of endocannabinoid system may function as an inhibitory feedback mechanism aimed at limiting the cocaine-mediated effects. In this line, in fact, it has been found that pretreatment with the cannabinoid antagonist SR141716A enhanced the stimulation of motor behavior induced by the D2-like receptor agonist quinpirole (Giuffrida et al, 1999), while the inhibition of intracellular transport of AEA reduced its effects (Beltramo et al, 2000).

In our experimental condition, however, D2-like receptorstimulated AEA production enhanced the effects of cocaine in the striatum, through the stimulation of $\mathrm{CB} 1$ receptors. The cooperative action of D2-like and $\mathrm{CB} 1$ receptors is supported by at least two experimental findings. First, endogenously produced endocannabinoids act as downstream effectors of D2 receptor signalling in the generation of corticostriatal long-term depression, a form of synaptic plasticity believed to underlie specific aspects of psychostimulant addiction (Gerdeman et al, 2002, 2003). Second, both D2 and CB1 receptors are expressed on GABA terminals of the striatum (Hermann et al, 2002; Delgado et al, 2000; Iversen, 2003), and the activation of both receptors reduces cAMP levels and transmitter release through an inhibitory G protein (Stoof and Kebabian, 1981; Pertwee, 1997; Vallone et al, 2000; Iversen, 2003).

Other experimental data indicate that cannabinoids and D2 receptors play synergistic actions in the brain. For example, concomitant activation of DA D2-like receptors by endogenous DA has been found to play a role in the THCinduced memory impairment and reduction of extracellular acetylcholine concentration in the hippocampus (Nava et al, 2000), while D2, but not D1 receptor agonists, potentiate cannabinoid-induced sedation in non-human primates (Meschler et al, 2000). In addition, the alteration in Fos expression that follows the blockade of CB1 receptors has been found to occur via reduced D2-like receptor-mediated function (Alonso et al, 1999). Furthermore, D2 (but also D1) receptors participate in the $\mathrm{THC}$-induced activation of the mitogen-activated protein kinase/extracellular signalregulated kinase (MAPK/ERK) in the dorsal striatum (Valjent et al, 2001). Finally, differential regulation of AEA by distinct DA receptors has also been reported within mouse limbic forebrain (Patel et al, 2003). Interestingly, a recent electrophysiological study showed that $\mathrm{CB} 1$ receptors mediate the long-term effects of amphetamine in the amygdala, independently of DA, serotonin, and noradrenaline transmission (Huang et al, 2003). Our neurophysiological findings, however, do not contradict the role of anandamide as a stop signal for DA, since the nature of the interaction between these two transmitter systems might ultimately depend on a series of variables, including the physiological state of striatal neurons in vivo.

\section{DA-Cannabinoid Interaction in the Modulation of GABAergic Transmission in the Striatum}

In the present work, we have found that cocaine-stimulated AEA significantly contributes to inhibit GABA-mediated synaptic transmission in the striatum, thereby favoring neuronal excitation. Striatal neuron firing activity, in fact, is governed by both glutamate-mediated excitatory synaptic inputs and GABA-dependent inhibitory potentials, which efficiently contrast the excitatory action of glutamate (Kita, 1996; Plenz and Kitai, 1998). Accordingly, in vivo, blockade of ongoing GABAergic inhibition of striatal neurons has been found to elevate significantly basal activity of these cells (Nisenbaum and Berger, 1992). 
GABAergic innervation of striatal cells is essentially intrinsic, as recurrent collaterals of projection neurons and GABAergic interneurons virtually represent the totality of their inhibitory inputs (Plenz and Kitai, 1998; Koos and Tepper, 1999; Tunstall et al, 2002). Among the various GABAergic inputs to spiny neurons, those originating from fast-spiking interneurons seem to exert the prominent inhibitory control on the functional activity of these cells (Plenz and Kitai, 1998; Koos and Tepper, 1999). Since these GABAergic interneurons are a preferential location of cannabinoid CB1 receptors in the striatum (Hohmann and Herkenham, 2000), where they act to inhibit GABA release (Iversen, 2003; Piomelli, 2003), it is possible that the IPSCs measured in our study were those originating from the activity of these cells, as they were modulated by cocaine through the engagement of cannabinoid CB1 receptors.

\section{Concluding Remarks}

From behavioral studies, it is increasingly clear that endocannabinoids, rather than contributing to the hedonic and psychomotor effects of cocaine assumption, play a central role in the generation and maintenance of addictive behavior, which is commonly believed to reflect the aberrant engagement of synaptic plasticity (long-term depression (LTD) and long-term potentiation (LTP)) at excitatory corticostriatal synapses (Everitt and Wolf, 2002; Gerdeman et al, 2003).

The endocannabinoid-dependent inhibition of GABA inputs might favor synaptic plasticity at excitatory corticostriatal synapses by enhancing the level of postsynaptic depolarization required for the induction of both LTP and LTD (Centonze et al, 2001). In this line, it has recently been shown that cannabinoid-dependent inhibition of GABA transmission may actually facilitate the emergence of synaptic plasticity at excitatory synapses in the hippocampus (Carlson et al, 2002).

In conclusion, we have demonstrated that cocaine significantly perturbs endocannabinoid system in the striatum, and we have identified a possible mechanism by which this perturbation modulates the cellular mechanisms of drug addiction.

\section{ACKNOWLEDGEMENTS}

We thank Mr M Tolu for his technical assistance. This work was supported by a Progetto Finalizzato Schizofrenia (Fondazione Santa Lucia) to PC, by a Progetto Ministero della Salute (Ricerca Finalizzata 2004) to MM, and by two Ministero dell'Università e della Ricerca Scientifica e Tecnologica, Consiglio Nazionale delle Ricerche Biotechnology Programs (L 95/95) to GB and AF-A.

\section{REFERENCES}

Alonso R, Voutsinos B, Fournier M, Labie C, Steinberg R, Soulhac J et al (1999). Blockade of cannabinoid receptors by SR 141716 selectively increases fos expression in rat mesocorticolimbic areas via reduced dopamine D2 function. Neuroscience 91: 607-620.
Amalric M, Koob GF (1993). Functionally selective neurochemical afferents and efferents of the mesocorticolimbic and nigrostriatal dopamine system. Prog Brain Res 99: 209-226.

Barker EL, Blakely RD (1995). Norepinephrine and serotonin transporters. Molecular targets of antidepressant drugs. In: Bloom FS, Kupfer DJ (eds). Psychopharmacology: The Fourth Generation of Progress. Raven Press Ltd: New York. pp 321-333.

Beltramo M, de Fonseca FR, Navarro M, Calignano A, Gorriti MA, Grammatikopoulos $\mathrm{G}$ et al (2000). Reversal of dopamine $\mathrm{D}(2)$ receptor responses by an anandamide transport inhibitor. J Neurosci 20: 3401-3407.

Berdyshev EV, Schmid PC, Dong Z, Schmid HH (2000). Stressinduced generation of $N$-acylethanolamines in mouse epidermal JB6 $\mathrm{P}^{+}$cells. Biochem J 346: 369-374.

Berke JD, Hyman SE (2000). Addiction, dopamine, and the molecular mechanisms of memory. Neuron 25: 515-532.

Breivogel CS, Griffin G, Di Marzo V, Martin BR (2001). Evidence for a new $G$ protein-coupled cannabinoid receptor in mouse brain. Mol Pharmacol 60: 155-163.

Cadas H, di Tomaso E, Piomelli D (1997). Occurrence and biosynthesis of endogenous cannabinoid precursors, $\mathrm{N}$-arachidonoyl phosphatidylethanolamine, in rat brain. J Neurosci 17: 1226-1242.

Calabresi P, Centonze D, Bernardi G (2000). Electrophysiology of dopamine in normal and denervated striatal neurons. Trends Neurosci 23(Suppl 10): S57-63.

Calabresi P, De Murtas M, Bernardi G (1997). The neostriatum beyond the motor function: experimental and clinical evidence. Neuroscience 78: 39-60.

Canales JJ, Graybiel AM (2000). A measure of striatal function predicts motor stereotypy. Nat Neurosci 3: 377-383.

Carlson G, Wang Y, Alger BE (2002). Endocannabinoids facilitate the induction of LTP in the hippocampus. Nat Neurosci 5: 723-724.

Carlsson A, Waters N, Holm-Waters S, Tedroff J, Nilsson M, Carlsson ML (2001). Interactions between monoamines, glutamate and GABA in schizophrenia: new evidence. Ann Rev Pharmacol Toxicol 41: 237-260.

Centonze D, Grande C, Usiello A, Gubellini P, Erbs E, Martin AB et al (2003). Receptor subtypes involved in the presynaptic and postsynaptic actions of dopamine on striatal interneurons. J Neurosci 23: 6245-6254.

Centonze D, Picconi B, Baunez C, Borrelli E, Pisani A, Bernardi G et al (2002). Cocaine and amphetamine depress striatal GABAergic synaptic transmission through D2 dopamine receptors. Neuropsychopharmacology 26: 164-175.

Centonze D, Picconi B, Gubellini P, Bernardi G, Calabresi P (2001). Dopaminergic control of synaptic plasticity in the dorsal striatum. Eur J Neurosci 13: 1071-1077.

Chaperon F, Soubrie P, Puech AJ, Thiebot MH (1998). Involvement of central cannabinoid (CB1) receptors in the establishment of place conditioning in rats. Psychopharmacology 135: 324-332.

Coutts AA, Anavi-Goffer S, Ross RA, MacEwan DJ, Mackie K, Pertwee RG et al (2001). Agonist-induced internalization and trafficking of cannabinoid $\mathrm{CB} 1$ receptors in hippocampal neurons. J Neurosci 21: 2425-2433.

Delgado A, Sierra A, Querejeta E, Valdiosera RF, Aceves J (2000). Inhibitory control of the GABAergic transmission in the rat neostriatum by D2 dopamine receptors. Neuroscience 95: 1043-1048.

De Vries TJ, Shaham Y, Homberg JR, Crombag H, Schuurman K, Dieben $J$ et al (2001). A cannabinoid mechanism in relapse to cocaine seeking. Nat Med 7: 1151-1154.

Di Marzo V, Fontana A, Cadas H, Schinelli S, Cimino G, Schwartz JC et al (1994). Formation and inactivation of endogenous cannabinoid anandamide in central neurons. Nature 372: 686-691. 
Di Marzo V, Hill MP, Bisogno T, Crossman AR, Brotchie JM (2000). Enhanced levels of endogenous cannabinoids in the globus pallidus are associated with a reduction in movement in an animal model of Parkinson's disease. FASEB $J$ 14: 1432-1438.

Emrich HM, Leweke FM, Schneider U (1997). Towards a cannabinoid hypothesis of schizophrenia: cognitive impairments due to dysregulation of the endogenous cannabinoid system. Pharmacol Biochem Behav 56: 803-807.

Everitt BJ, Wolf ME (2002). Psychomotor stimulant addiction: a neural systems perspective. J Neurosci 22: 3312-3320.

Gerdeman GL, Partridge JG, Lupica CR, Lovinger DM (2003). It could be habit forming: drugs of abuse and striatal synaptic plasticity. Trends Neurosci 26: 184-192.

Gerdeman GL, Ronesi J, Lovinger DM (2002). Postsynaptic endocannabinoid release is critical to long-term depression in the striatum. Nat Neurosci 5: 446-451.

Giuffrida A, Parsons LH, Kerr TM, Rodriguez de Fonseca F, Navarro M, Piomelli D (1999). Dopamine activation of endogenous cannabinoid signaling in dorsal striatum. Nat Neurosci 2: 358-363.

Gorriti MA, Rodriguez de Fonseca F, Navarro M, Palomo T (1999). Chronic (-)-delta-9-tetrahydrocannabinol treatment induces sensitization to the psychomotor effects of amphetamine in rats. Eur J Pharmacol 365: 133-142.

Graybiel AM, Moratalla R, Robertson HA (1990). Amphetamine and cocaine induce drug-specific activation of the c-fos gene in striosome-matrix compartments and limbic subdivisions of the striatum. Proc Natl Acad Sci USA 87: 6912-6916.

Gubellini P, Picconi B, Bari M, Battista N, Calabresi P, Centonze D et al (2002). Experimental parkinsonism alters endocannabinoid degradation: implications for striatal glutamatergic transmission. J Neurosci 22: 6900-6907.

Hermann H, Marsicano G, Lutz B (2002). Coexpression of the cannabinoid receptor type 1 with dopamine and serotonin receptors in distinct neuronal subpopulations of the adult mouse forebrain. Neuroscience 109: 451-460.

Hohmann AG, Herkenham M (2000). Localization of cannabinoid $\mathrm{CB} 1$ receptor mRNA in neuronal subpopulations of rat striatum: a double-label in situ hybridization study. Synapse 37: 71-80.

Hsieh C, Brown S, Derleth C, Mackie K (1999). Internalization and recycling of the CB1 cannabinoid receptor. J Neurochem 73 493-501.

Huang YC, Wang SJ, Chiou LC, Gean PW (2003). Mediation of amphetamine-induced long-term depression of synaptic transmission by $\mathrm{CB} 1$ cannabinoid receptors in the rat amygdala. J Neurosci 23: 10311-10320.

Hyman SE, Malenka RC (2001). Addiction and the brain: the neurobiology of compulsion and its persistence. Nat Rev Neurosci 2: 695-703.

Iversen L (2003). Cannabis and the brain. Brain 126: 1252-1270.

Jog MS, Kubota Y, Connolly CI, Hillegaart V, Graybiel AM (1999). Building neural representations of habit. Science 286: $1745-1749$.

Johanson C-E, Schuster CR (1995). Cocaine. In: Bloom FE, Kupfer DJ (eds). Psychopharmacology: The Fourth Generation of Progress. Raven Press Ltd: New York. pp 1685-1697.

Kelly PH, Seviour PW, Iversen SD (1975). Amphetamine and apomorphine responses in the rat following 6-OHDA lesions of the nucleus accumbens septi and corpus striatum. Brain Res 94: 507-522.

Kita H (1996). Glutamatergic and GABAergic postsynaptic responses of striatal spiny neurons to intrastriatal and cortical stimulation recorded in slice preparations. Neuroscience 70: 925-940.

Kiyatkin EA, Rebec GV (2000). Dopamine-independent action of cocaine on striatal and accumbal neurons. Eur I Neurosci 12 $1789-1800$
Koos T, Tepper JM (1999). Inhibitory control of neostriatal projection neurons by GABAergic interneurons. Nat Neurosci 2: 467-472.

Leckman JF, Riddle MA (2000). Tourette's syndrome: when habit-forming systems form habits of their own? Neuron 28: 349-354.

Ledent C, Valverde O, Cossu G, Petitet F, Aubert JF, Beslot F et al (1999). Unresponsiveness to cannabinoids and reduced addictive effects of opiates in CB1 receptor knockout mice. Science 283: 401-404.

Maccarrone $\mathrm{M}$, Attinà $\mathrm{M}$, Bari $\mathrm{M}$, Cartoni $\mathrm{A}$, Ledent $\mathrm{C}$, FinazziAgrò A (2001). Anandamide degradation and $\mathrm{N}$-acylethanolamines level in wild-type and CB1 cannabinoid receptor knockout mice of different ages. J Neurochem 78: 339-348.

Maccarrone M, Bari M, Di Rienzo M, Finazzi-Agrò A, Rossi A (2003b). Progesterone activates fatty acid amide hydrolase (FAAH) promoter in human $\mathrm{T}$ lymphocytes through the transcription factor Ikaros. Evidence for a synergistic effect of leptin. J Biol Chem 278: 32726-32732.

Maccarrone M, Di Rienzo M, Battista N, Gasperi V, Guerrieri P, Rossi A et al (2003c). The endocannabinoid system in human keratinocytes. Evidence that anandamide inhibits epidermal differentiation through CB1 receptor-dependent inhibition of protein kinase $\mathrm{C}$, activating protein-1 and transglutaminase. J Biol Chem 278: 33896-33903.

Maccarrone M, Fezza F, Finazzi-Agrò A (2004). Levels of $N$ acylethanolamines in human tumors: in search of reliable data. Lipids 39, (in press).

Maccarrone M, Gubellini P, Bari M, Picconi B, Battista N, Centonze $\mathrm{D}$ et al (2003a). Levodopa treatment reverses endocannabinoid system abnormalities in experimental parkinsonism. J Neurochem 85: 1018-1025.

Maldonado R, Rodriguez de Fonseca F (2002). Cannabinoid addiction: behavioral models and neural correlates. J Neurosci 22: 3326-3331.

Mansour A, Watson SJ (1995). Dopamine receptor expression in the central nervous system. In: Bloom FE, Kupfer DJ (eds). Psychopharmacology: The Fourth Generation of Progress. Raven Press Ltd: New York. pp 207-219.

Martin M, Ledent C, Parmentier M, Maldonado R, Valverde O (2000). Cocaine, but not morphine, induces conditioned place preference and sensitization to locomotor responses in $\mathrm{CB} 1$ knockout mice. Eur J Neurosci 12: 4038-4046.

Meschler JP, Conley TJ, Howlett AC (2000). Cannabinoid and dopamine interaction in rodent brain: effects on locomotor activity. Pharmacol Biochem Behav 67: 567-573.

Moesgaard B, Petersen G, Jaroszewski JW, Hansen HS (2000). Age dependent accumulation of $\mathrm{N}$-acyl-ethanolamine phospholipids in ischemic rat brain. A ${ }^{31} \mathrm{P}$ NMR and enzyme activity study. J Lipid Res 41: 985-990.

Moratalla R, Vickers EA, Robertson HA, Cochran BH, Graybiel AM (1993). Coordinate expression of c-fos and junB is induced in the rat striatum by cocaine. J Neurosci 13: 423-433.

Nava F, Carta G, Battasi AM, Gessa GL (2000). D(2) dopamine receptors enable delta(9)-tetrahydrocannabinol induced memory impairment and reduction of hippocampal extracellular acetylcholine concentration. Br J Pharmacol 130: 1201-1210.

Navarro M, Chowen JA, Carrera MR, Del Arco I, Villanua MA, Martin Y et al (1998). CB1 cannabinoid receptor antagonistinduced opiate withdrawal in morphine-dependent rats. Neuroreport 9: 3397-3402.

Nisenbaum ES, Berger TW (1992). Functionally distinct subpopulations of striatal neurons are differentially regulated by GABAergic and dopaminergic inputs. I. In vivo analysis. Neuroscience 48: 561-578.

Obeso JA, Rodríguez-Oroz MC, Rodríguez M, Lanciego JL, Artieda J, Gonzalo N et al (2000). Pathophysiology of the basal ganglia in Parkinson's disease. Trends Neurosci 23(10 Suppl): S8-S19. 
Okamoto Y, Morishita J, Tsuboi K, Tonai T, Ueda N (2004). Molecular characterization of a phospholipase $\mathrm{D}$ generating anandamide and its congeners. J Biol Chem 279: 5298-5305.

Packard MG, Knowlton BJ (2002). Learning and memory functions of the basal ganglia. Annu Rev Neurosci 25: 563-593.

Patel S, Rademacher DJ, Hillard CJ (2003). Differential regulation of the endocannabinoids anandamide and 2-arachidonylglycerol within the limbic forebrain by dopamine receptor activity. J Pharmacol Exp Ther 306: 880-888.

Pertwee RG (1997). Pharmacology of cannabinoid CB1 and CB2 receptors. Pharmacol Ther 74: 129-180.

Pertwee RG, Ross RA (2002). Cannabinoid receptors and their ligands. Prostag Leukotr Essential Fatty Acids 66: 101-121.

Picconi B, Centonze D, Hakansson K, Bernardi G, Greengard P, Fisone $G$ et al (2003). Loss of bidirectional striatal synaptic plasticity in L-DOPA-induced dyskinesia. Nat Neurosci 6: 501-506.

Piomelli D (2003). The molecular logic of endocannabinoid signalling. Nat Rev Neurosci 4: 873-884.

Pisani A, Bonsi P, Centonze D, Martorana A, Fusco F, Sancesario G et al (2003). Activation of beta1-adrenoceptors excites striatal cholinergic interneurons through a cAMP-dependent, protein kinase-independent pathway. J Neurosci 23: 5272-5282.

Plenz D, Kitai ST (1998). Up and down states in striatal medium spiny neurons simultaneously recorded with spontaneous activity in fast-spiking interneurons studied in cortex-striatum-substantia nigra organotypic cultures. J Neurosci 18: 266-283.

Pontieri FE, Monnazzi P, Scontrini A, Buttarelli FR, Patacchioli FR (2001). Behavioral sensitization to heroin by cannabinoid pretreatment in the rat. Eur J Pharmacol 421: R1-R3.

Schmid PC, Paria BC, Krebsbach RJ, Schmid HHO, Dey SK (1997). Changes in anandamide levels in mouse uterus are associated with uterine receptivity for embryo implantation. Proc Natl Acad Sci USA 94: 4188-4192.

Stoof JC, Kebabian JW (1981). Opposing roles for D-1 an D-2 dopamine receptors in efflux of cyclic AMP from rat neostriatum. Nature 294: 366-368.

Surmeier DJ, Song W-J, Yan Z (1996). Coordinated expression of dopamine receptors in neostriatal medium spiny neurons. J Neurosci 16: 6579-6591.

Szabo B, Dorner L, Pfreundtner C, Norenberg W, Starke K (1998). Inhibition of GABAergic inhibitory postsynaptic currents by cannabinoids in rat corpus striatum. Neuroscience 85: 395-403.

Tanda G, Munzar P, Goldberg SR (2000). Self-administration behavior is maintained by the psychoactive ingredient of marijuana in squirrel monkeys. Nat Neurosci 3: 1073-1074.

Tunstall MJ, Oorschot DE, Kean A, Wickens JR (2002). Inhibitory interactions between spiny projection neurons in the rat striatum. J Neurophysiol 88: 1263-1269.

Valjent E, Pages C, Rogard M, Besson MJ, Maldonado R, Caboche J (2001). Delta 9-tetrahydrocannabinol-induced MAPK/ERK and Elk-1 activation in vivo depends on dopaminergic transmission. Eur J Neurosci 14: 342-352.

Vallone D, Picetti P, Borrelli E (2000). Structure and function of dopamine receptors. Neurosci Biobehav Rev 24: 125-132.

Wilms K, Vierig G, Davidowa H (2001). Interactive effects of cholecystokinin-8S and various serotonin receptor agonists on the firing activity of neostriatal neurones in rats. Neuropeptides 35: 257-270.

Yang H-YT, Karoum F, Felder C, Badger H, Wang T-CL, Markey SP (1999). GC/MS analysis of anandamide and quantification of $\mathrm{N}$-arachidonoyl-phosphatidylethanolamides in various brain regions, spinal cord, testis, and spleen of the rat. J Neurochem 72: 1959-1968. 